\title{
Home spirometry to assess efficacy of pirfenidone in progressive unclassifiable interstitial lung disease: better the devil you know than the devil you don't
}

\author{
Giacomo Sgalla $^{1 \wedge}$, Pier-Valerio Mari $^{2}$, Luca Richeldi $^{1,2}$ \\ ${ }^{1}$ UOC Pneumologia, Dipartimento Scienze Gastroenterologiche, Endocrino-Metaboliche e Nefro-Urologiche, Fondazione Policlinico Universitario \\ “A. Gemelli” IRCCS, Rome, Italy; ${ }^{2}$ Università Cattolica del Sacro Cuore, Rome, Italy \\ Correspondence to: Luca Richeldi. Fondazione Policlinico Universitario A. Gemelli, Largo Agostino Gemelli 8, Rome 00168, Italy. Email: luca. \\ richeldi@policlinicogemelli.it. \\ Comment on: Maher TM, Corte TJ, Fischer A, et al. Pirfenidone in patients with unclassifiable progressive fibrosing interstitial lung disease: a double- \\ blind, randomised, placebo-controlled, phase 2 trial. Lancet Respir Med 2020;8:147-57.
}

Submitted Apr 10, 2020. Accepted for publication Jun 02, 2020.

doi: $10.21037 /$ atm-20-3243

View this article at: http://dx.doi.org/10.21037/atm-20-3243

Interstitial lung diseases (ILDs) are a complex of heterogeneous disorders characterized by varying degrees of inflammation and scarring of the lung interstitium while generally sharing a poor prognosis quoad vitam et valetudinem (1). Since 2002, the American Thoracic Society (ATS) and the European Respiratory Society (ERS) advocated a multidisciplinary team (MDT) approach involving clinicians, radiologists and pathologists in an active process to increase diagnostic accuracy in patients with ILD (2) and therefore guide the appropriate choice of treatment. MDT meetings are currently considered the gold standard for the diagnosis of ILD as they have been shown to improve the diagnostic confidence as compared to individual specialists $(3,4)$, despite some limitations exist such as the lack of specific guidelines for the optimal structure or the evidence in non-specialized centers (5). In the course of the last two decades, the scientific community particularly focused on making an accurate diagnosis of idiopathic pulmonary fibrosis (IPF) (6-8), the most severe of idiopathic interstitial pneumonias. Such efforts led to the standardization of the diagnostic approach worldwide, to significant advances in the understanding of underlying disease pathogenesis and, ultimately, to outstanding therapeutic achievements represented by the approval of pirfendone and nintedanib, the first antifibrotic treatments proving to slow down the lung function decline in these patients $(9,10)$. While the agreement between multidisciplinary teams has shown to be good for a diagnosis of IPF, disagreement on diagnosis of other forms such as non specific interstitial pneumonias or chronic hypersensitivity pneumonitis is more common (4), mostly due to the lack of consesus-based guidelines. Moreover, when a thorough MDT evaluation cannot assign more than $50 \%$ confidence to an ILD diagnosis, the diagnostic process fails to yield a specific classification: these patients are assigned a diagnosis of unclassifiable ILD (U-ILD) (11) and are therefore left without evidence-based therapeutic options. Yet, the conclusion that unclassifiable ILD means untreatable disease should not be endorsed (12). Indeed, IPF and other ILDs have pathobiological similarities and may share a progressive fibrosing phenotype that could be susceptible of the same anti-fibrotic treatments approved for IPF (13). The phase 3 INBUILD study already demonstrated the efficacy of nintedanib in reducing FVC decline over 52 weeks in patients with progressive fibrosing interstitial lung disease (PF-ILD), including patients with U-ILD (14). In their work, Maher and coauthors (15) answered the call for a randomized controlled trial of pirfenidone in progressive fibrosing ILDs, focusing on a population with unclassifiable forms and thus placing a first

^ ORCID: 0000-0003-3130-9388. 
milestone in the challenging path of U-ILD therapy.

This multicenter, double-blind, placebo-controlled, phase II clinical trial aimed to assess the efficacy of pirfenidone for the treatment of U-ILD by using daily home spirometry via handheld device. The authors ambitiously set the mean change of forced vital capacity (FVC) at 24 weeks as the primary endpoint, building upon previous reports that IPF progression could be reliably assessed via home spirometry (16). The required single daily measurement of FVC allowed maximize the compliance of study participants, however such choice resulted in a remarkably high intraindividual variability of FVC values, impairing the application of the planned statistical model to the primary endpoint data. As such, the trial design disappointingly prevented from obtaining proof of efficacy of pirfenidone using home spirometry, raising questions as to the choice of the primary endpoint for this study. Although measurement of pulmonary function at the study site is time consuming and requires specific staff training, it provides extremely reliable assessments through bulletproof quality checks. Most importantly, two decades of randomized clinical trials in IPF confirmed bysite FVC measurement as the most robust clinical endpoint to assess functional deterioration in these patients. In the approaching era of telemedicine, handheld spirometers represent indeed an attractive tool to monitor disease behavior in patients with chronic respiratory disorders; nevertheless, home monitoring experiences in ILD populations are still limited, and these devices have not yet been implemented in daily practice. Following an earlier report of self-monitoring of pulmonary function using a home spirometer (16), a study investigated the reliability, feasibility, and impact of home-based measurement of forced vital capacity (FVC) and dyspnea in a US population of IPF patients (17). Patients performed weekly homebased assessments of FVC and dyspnea using a mobile handheld spirometer and self-administered questionnaires. Mean adherence to measurements of FVC over 24 weeks was greater than $90 \%$, and the weekly assessment schedule resulted in increased precision and power for a hypothetical 24-week clinical trial as compared with baseline and 24-week measurements only. Another study conducted in a specialised centre in the Netherlands confirmed feasibility of a home monitoring program including realtime wireless home spirometry in IPF patients (18). In this scenario, the courageous choice made by the authors to incorporate home spirometry as the primary endpoint in a ILD pharmaceutical trial is commendable, but the study results underline the need for a better validation of these devices before they could be strategically implemented in the design of future research.

On the other hand, the study by Maher and coworkers delivered substantial evidence on the efficacy of pirfenidone as compared to placebo with regards to several secondary endpoints. When compared to placebo, treatment with pirfenidone significantly reduced the decline in FVC at 24 weeks by a mean difference $(95.3 \mathrm{~mL}, 95 \% \mathrm{CI}$ : 35.9 to $154.6, \mathrm{P}=0.002)$ that is in line with the results of pirfenidone phase III trials in IPF $(9,19)$. Such benefit was also shown in terms of categorical decline of FVC: an absolute decline of more than $10 \%$ of the predicted $\mathrm{FVC}$ was observed in 18 ( $\mathrm{n}=127,14 \%)$ patients in the pirfenidone group when compared to the $34(\mathrm{n}=126,27 \%)$ patients in the placebo group [odds ratio (OR): $0.44,95 \%$ CI: 0.23 to $0.84, \mathrm{P}=0.011]$. An impact of the antifibrotic treatment on the reduction of diffusion capacity of carbon dioxide $\left(\mathrm{DL}_{\mathrm{CO}}\right)$ was also shown, since only $3(2 \%)$ patients in the pirfenidone group underwent significant $(>15 \%$ of predicted DLco) decline as compared to $11(9 \%)$ in the placebo group (OR: $0.25,95 \%$ CI: 0.07 to $0.93, \mathrm{P}=0.039$ ). Finally, the 24-week mean change in 6-min walking distance (6MWD) also favored pirfenidone over placebo. Considering the statistical limitations due to small sample sizes, the exploratory investigations suggested that pirfenidone might be beneficial across different subgroups of unclassifiable ILD: a greater treatment effect on FVC change at 24-week was pointed out in the following subgroups: males (108.5 mL, $\mathrm{P}=0.0167), \geq 65$ years $(122.5 \mathrm{~mL}, \mathrm{P}=0.0018)$, predicted $\mathrm{FVC} \geq 80 \%(137.3 \mathrm{~mL}, \mathrm{P}=0.0105)$, corrected $\mathrm{DL}_{\mathrm{CO}} \geq 35 \%$ (81.6 mL, $\mathrm{P}=0.0149$ ), baseline weight $\geq 60 \mathrm{~kg}$ (103.9 mL, $\mathrm{P}=0.0004)$, absence of interstitial pneumonia with autoimmune features (IPAF) $(121.5 \mathrm{~mL}, \mathrm{P}=0.0024)$. Importantly, no new concerns were raised with regards to the tolerability and safety profile of pirfenidone, that showed a comparable profile with previous phase III clinical trials in IPF (9).

In summary, overlooking the disappointing findings with regard to the primary endpoint, the study by Maher and coworkers convincingly supports the efficacy of pirfenidone in slowing down FVC decline in patients with progressive unclassifiable ILD, thus paving the way for a therapeutic approach even when a consensus diagnosis cannot be achieved. Although the results on secondary endpoints should be interpreted with caution, they are encouraging for ongoing investigations of antifibrotics in progressive fibrosing ILD (20), and definitely warrant further research 
investigating the role of pirfenidone in treating the unclassifiable ILD population in the longer term.

\section{Acknowledgments}

Funding: None.

\section{Footnote}

Provenance and Peer Review: This article was commissioned by the editorial office, Annals of Translational Medicine. The article did not undergo external peer review.

Conflicts of Interest: All authors have completed the ICMJE uniform disclosure form (available at http://dx.doi. org/10.21037/atm-20-3243). SG has received personal fees from Boehringer Ingelheim outside the submitted work. RL has received grants and personal fees from Boehringer Ingelheim and InterMune, and personal fees from BiogenIdec, ImmuneWorks, Medimmune, Roche, Sanofi-Aventis, Shionogi, and Takeda outside of the submitted work. The other authors have no conflicts of interest to declare.

Ethical Statement: The authors are accountable for all aspects of the work in ensuring that questions related to the accuracy or integrity of any part of the work are appropriately investigated and resolved.

Open Access Statement: This is an Open Access article distributed in accordance with the Creative Commons Attribution-NonCommercial-NoDerivs 4.0 International License (CC BY-NC-ND 4.0), which permits the noncommercial replication and distribution of the article with the strict proviso that no changes or edits are made and the original work is properly cited (including links to both the formal publication through the relevant DOI and the license). See: https://creativecommons.org/licenses/by-nc-nd/4.0/.

\section{References}

1. Antoniou KM, Margaritopoulos GA, Tomassetti S, et al. Interstitial lung disease. Eur Respir Rev 2014;23:40-54.

2. American Thoracic Society; European Respiratory Society. American Thoracic Society/European Respiratory Society International Multidisciplinary Consensus Classification of the Idiopathic Interstitial Pneumonias. This joint statement of the American Thoracic Society (ATS), and the European Respiratory Society (ERS) was adopted by the ATS board of directors, June 2001 and by the ERS Executive Committee, June 2001. Am J Respir Crit Care Med 2002;165:277-304.

3. Flaherty KR, King TE Jr, Raghu G, et al. Idiopathic interstitial pneumonia: what is the effect of a multidisciplinary approach to diagnosis? Am J Respir Crit Care Med 2004;170:904-10.

4. Walsh SLF, Wells AU, Desai SR, et al. Multicentre evaluation of multidisciplinary team meeting agreement on diagnosis in diffuse parenchymal lung disease: a casecohort study. Lancet Respir Med 2016;4:557-65.

5. Richeldi L, Launders N, Martinez F, et al. The characterisation of interstitial lung disease multidisciplinary team meetings: a global study. ERJ Open Res 2019;5:00209-2018.

6. Varone F, Inoue Y, Richeldi L. Twenty-five years of Respirology: Advances in idiopathic pulmonary fibrosis. Respirology 2020;25:20-2.

7. Sgalla G, Kulkarni T, Antin-Ozerkis D, et al. Update in Pulmonary Fibrosis 2018. Am J Respir Crit Care Med 2019;200:292-300.

8. Mari PV, G Jones M, Richeldi L. Contemporary Concise Review 2018: Interstitial lung disease. Respirology 2019;24:809-16.

9. King TE Jr, Bradford WZ, Castro-Bernardini S, et al. A Phase 3 Trial of Pirfenidone in Patients with Idiopathic Pulmonary Fibrosis. N Engl J Med 2014;370:2083-92.

10. Richeldi L, du Bois RM, Raghu G, et al. Efficacy and Safety of Nintedanib in Idiopathic Pulmonary Fibrosis. N Engl J Med 2014;370:2071-82.

11. Ryerson CJ, Corte TJ, Lee JS, et al. A Standardized Diagnostic Ontology for Fibrotic Interstitial Lung Disease. An International Working Group Perspective. Am J Respir Crit Care Med 2017;196:1249-54.

12. Oldham JM. Interstitial lung disease: perhaps unclassifiable, but not untreatable. Lancet Respir Med 2020;8:126-7.

13. Richeldi L, Varone F, Bergna M, et al. Pharmacological management of progressive-fibrosing interstitial lung diseases: a review of the current evidence. Eur Respir Rev 2018;27:180074.

14. Flaherty KR, Wells AU, Cottin V, et al. Nintedanib in Progressive Fibrosing Interstitial Lung Diseases. N Engl J Med 2019;381:1718-27.

15. Maher TM, Corte TJ, Fischer A, et al. Pirfenidone in patients with unclassifiable progressive fibrosing interstitial lung disease: a double-blind, randomised, placebocontrolled, phase 2 trial. Lancet Respir Med 2020;8:147-57.

16. Russell AM, Adamali H, Molyneaux PL, et al. Daily Home 
Spirometry: An Effective Tool for Detecting Progression in Idiopathic Pulmonary Fibrosis. Am J Respir Crit Care Med 2016;194:989-97.

17. Johannson KA, Vittinghoff E, Morisset J, et al. Home monitoring improves endpoint efficiency in idiopathic pulmonary fibrosis. Eur Respir J 2017;50:1602406.

18. Moor CC, Wapenaar M, Miedema JR, et al. A home monitoring program including real-time wireless home spirometry in idiopathic pulmonary fibrosis: A pilot study on experiences and barriers. Respir Res 2018;19:105.

19. Noble PW, Albera C, Bradford WZ, et al. Pirfenidone in patients with idiopathic pulmonary fibrosis (CAPACITY): Two randomised trials. Lancet 2011;377:1760-9.

20. Goldberg HJ. Understanding Progressive Fibrosing Interstitial Lung Disease through Therapeutic Trials. N Engl J Med 2019;381:1775-7.
Cite this article as: Sgalla G, Mari PV, Richeldi L. Home spirometry to assess efficacy of pirfenidone in progressive unclassifiable interstitial lung disease: better the devil you know than the devil you don't. Ann Transl Med 2020;8(23):1615. doi: 10.21037/atm-20-3243 